8 Hammond SR, English DR, McLeod JG. The age-range of risk of developing multiple sclerosis: evidence from a migrant population in Austin 2000;123:968-74

9 Hammond SR, McLeod JG, Millingen KS, Stewart-Wynne EG, English D, Holland JT, et al. The epidemiology of multiple sclerosis in three Australian cities: Perth, Newcastle and Hobart. Brain 1988;111:1-25.

10 Jones G, Blizzard C, Riley MD, Parameswaran V, Greenaway TM, Dwyer T. Vitamin D levels in prepubertal children in Southern Tasmania: prevalence and determinants. Eur J Clin Nutr 1999;53:824-9.

11 Garssen J, van Loveren H. Effects of ultraviolet exposure on the immune system. Crit Rev Immunol 2001:21:359-97.
12 Cantorna MT, Hayes CE, DeLuca HF. 1,25-Dihydroxyvitamin D3 reversibly blocks the progression of relapsing encephalomyelitis, a model of multiple sclerosis. Proc Natl Acad Sci USA 1996;93:7861-4.

13 Freedman DM, Dosemeci M, Alavanja MC. Mortality from multiple sclerosis and exposure to residential and occupational solar radiation: a casecontrol study based on death certificates. Occup Environ Med 2000;57:418-21

14 Hypponen E, Laara E, Reunanen A, Jarvelin MR, Virtanen SM. Intake of vitamin $\mathrm{D}$ and risk of type 1 diabetes: a birth-cohort study. Lancet 2001;358:1500-3.

(Accepted 3 June 2003)

\title{
Rate limiting factors in recruitment of patients to clinical trials in cancer research: descriptive study
}

\author{
Pippa Corrie, Justin Shaw, Roy Harris
}

Oncology Centre (Box 193),

Addenbrooke's

NHS Trust,

Cambridge

CB2 2QQ

Pippa Corrie

consultant and

associate lecturer in

medical oncology

Justin Shaw

clinical trials

coordinator

Roy Harris

research network

manager

Correspondence to:

P Corrie

pippa.corrie@

addenbrookes.nhs.uk

BMJ 2003;327:320-1
In 2004 the national cancer research network, established in 2001, will be evaluated on a performance target of increasing recruitment of patients into cancer clinical trials. The national average in 2000-1 was $3.5 \%$ of incident cancer cases and the target was set at $7.5 \%$. Much may depend on this target being met as $£ 11.5 \mathrm{~m}$ of government funding is being invested annually to provide infrastrucuture to conduct clinical trials within 34 networks across England. The future of this funding is not secure. We audited patients' involvement in clinical trials from a cohort of new cancer cases managed within a single research network to identify obstacles to recruitment.

\section{Participants, methods, and results}

The West Anglia cancer research network, a first wave regional research network, was established in 2001. It functions in close collaboration with the service based network. It covers a population of 1.65 million, and about 8000 new cases are seen each year. Patients discussed at weekly multidisciplinary team meetings are reviewed for their potential entry into trials. A database is kept of all patients considered for any clinical trial.

The figure summarises patients' data collected from team meetings in the cancer centre and four of the seven network cancer units during 2002. Of 1411 patients reviewed, 267 (19\%) eventually entered a trial (the overall recruitment rate for our network in 2002 was actually $10 \%)$. No trial was available for $561(40 \%)$ patients, and $390(28 \%)$ were immediately excluded as they failed entry criteria. Of the 460 patients considered potentially eligible for trial entry, only 19 $(4 \%)$ were not approached at all, $88(19 \%)$ declined to take part, and $59(13 \%)$ of those prepared to consider doing so ultimately failed screening procedures for specific trials. Overall, entry criteria disqualified 449 $(53 \%)$ of the 850 patients for whom a trial was available.

\section{Comment}

The main reasons for cancer patients not entering a trial were lack of an available study and failure to meet entry criteria. The task of doubling numbers of patients in cancer clinical trials by 2004 would therefore be made easier if a wider range of pragmatic trials was available. There is growing pressure on cancer specialists to

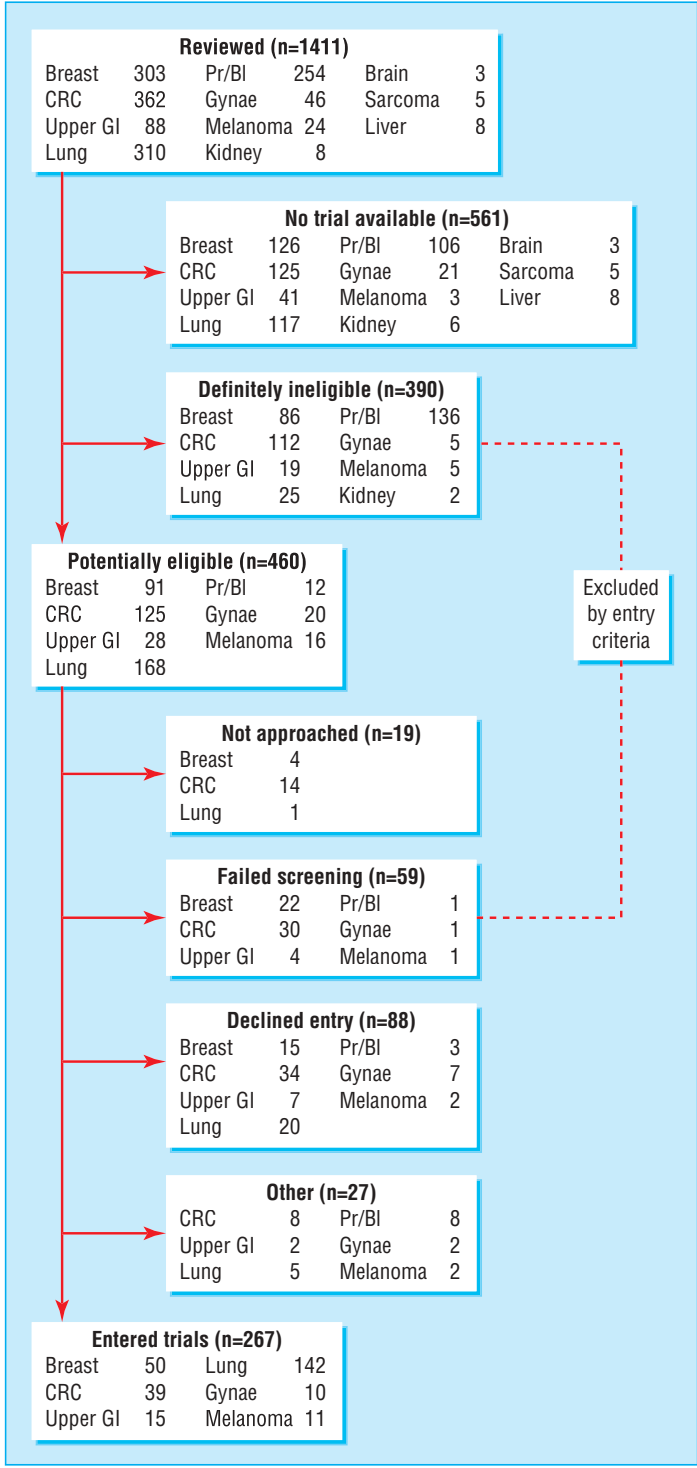

Outcome for patients reviewed for entry into clinical trials according to type of cancer $(\mathrm{CRC}=$ colorectal; $\mathrm{Pr} / \mathrm{Bl}=$ prostate/bladder; $\mathrm{Gl}=$ gastrointestinal). Where cancer type is not mentioned there were no relevant patients

ensure an active rolling national trial programme for each tumour type. Even so, funding for clinical research is limited. Research expenditure in the United Kingdom 
is over $£ 250 \mathrm{~m}$ annually, of which $22 \%$ goes on research into treatment ${ }^{1}$ and much of this is disproportionately channelled into "high profile" cancers such as breast, prostate, and leukaemia. ${ }^{2}$ Rare cancers with poor prognosis are frequently overlooked.

We found that even when a trial was available eligibility criteria excluded over half of patients. It is a common criticism that the outcomes of trials for new treatments are superior to those subsequently encountered in standard clinical practice. Trials with broad entry criteria that better reflect everyday life will help with recruitment of patients ${ }^{3}$ and probably yield more meaningful results.

Several national trials were not open for accrual in our research network because of lack of available service support and treatment costs. Although trusts are duty bound to provide support, our local research and development budgets are insufficient to meet the needs, while commissioners are in no financial position to be prioritising research over service needs. The onus must be on funding bodies and principal investigators of new trials to ensure adequate resourcing from the outset.

Finally, of those patients who were approached to enter a trial, one in five declined. Little is known about the factors that influence men and women to take part in clinical trials. ${ }^{4}$ There is much scope to involve consumers more actively in clinical research and encourage a partnership approach to improving cancer care.

We thank all nurses, clinicians, and other support staff of the West Anglia cancer research network involved in the conduct of cancer clinical trials. We especially thank those patients who agreed to take part in a trial.

Contributors: PC and JS were responsible for designing the study. JS analysed the data. PC interpreted the results, prepared the manuscript, and is guarantor. RH contributed to writing the report.

Funding: None.

Competing interests: None declared.

Ethical approval: All trials had local research ethics committee approval.

1 National Cancer Research Institute. Strategic analysis. An overview of cancer research in the UK directly funded by the NCRI partner organisations. London: NCRI, October 2002

2 Kmietowicz Z. Research spending on cancers doesn't match their death rates. BMJ 2001;325:920.

Baum M. The ATAC (arimidex, tamoxifen, alone or in combination) adjuvant breast cancer trial in postmenopausal patients: factors influencing the success of patient recruitment. Eur J Cancer 2002;38:1684-6.

4 Comis RL, Miller JD, Aldige CR, Krebs L, Stoval E. Public attitudes toward participation in cancer clinical trials. J Clin Oncol 2003;21:830-5.

(Accepted 27 May 2003)

\section{Effect of national guidelines on prescription of methadone: analysis of NHS prescription data, England 1990-2001}

John Strang, Janie Sheridan

Though there is strong evidence to support the use of methadone maintenance for opiate addiction ${ }^{1}$ it is often delivered poorly. Evidence based guidelines were developed in 1996 and 1999 (see www.doh.gov.uk/ drugdep.htm and further details on bmj.com) and widely publicised in the United Kingdom. ${ }^{2}{ }^{3}$ In 1998 we found scant evidence of any impact ${ }^{4}$ and concluded that "if planners are awaiting major change in methadone prescribing as a result of central exhortation, they should not hold their breath." However, perhaps guidelines may have a slower cumulative effect.

\section{Method and results}

We examined data on all NHS methadone prescriptions dispensed by community pharmacists in England. These account for $98 \%$ of methadone prescriptions in England. ${ }^{5}$ Unpublished commercial data indicate that $95 \%$ of methadone prescriptions from general practitioners are for addiction treatment (IMS Health).

To investigate the impact of the guidelines we used two specific recommendations from the Department of Health (the 1996 taskforce report and the Orange Guidelines 1999): firstly, that prescribing of methadone in tablet form should cease (based on concerns about intravenous misuse), and, secondly, that injectable methadone (methadone ampoules) should not be prescribed as mainstream treatment. We examined the proportion of methadone prescriptions per year issued as oral syrup, tablets, or injectable ampoules to identify any change of professional practice.

We examined the six years preceding 1996 (1990-5) to establish prevailing trends in methadone prescribing and then the six years during which the new guidelines were introduced (1996-2001) to study any change. Between 1990 and 2001, NHS prescriptions for methadone dispensed in England tripled-from 425400 to 1318100 annually-increasing every year. However, the proportionate annual increase fell from 15.3\%, 23.8\%, and $21.1 \%$ (first three years) down to increases of 2.7\%, $3.6 \%$, and $3.8 \%$ (last three years) (table).

Over the six year baseline period (1990-5), the proportion of methadone prescriptions prescribed as tablets was steady at between $7.8 \%$ and $9.8 \%$ annually. Thereafter, the proportion steadily reduced $(1 \%$ per annum) to $4.0 \%$ by 2001 , and the absolute number also fell every year. Similarly, prescriptions for injectable methadone were stable for 1990-5 (range $8.0 \%$ to $9.7 \%$, peaking at $9.7 \%$ in 1994) but steadily reduced thereafter, from $8.7 \%$ in 1995 to $3.9 \%$ in 2001 . From 1997 the absolute number of prescriptions as ampoules fell annually.

\section{Comment}

Over the past decade, the extent of methadone prescribing in England has tripled, deriving from a 